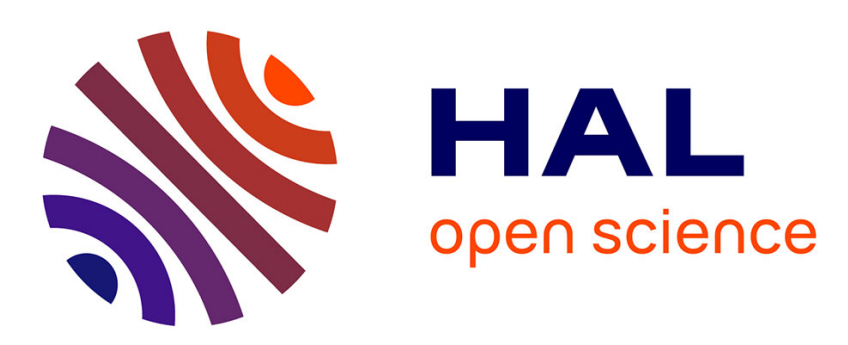

\title{
Local amplification of deep mining induced vibrations Part 1: Experimental evidence for site effects in a coal basin
}

Lynda Driad-Lebeau, Nabila Lokmane, Jean-François Semblat, Guy Bonnet

\section{- To cite this version:}

Lynda Driad-Lebeau, Nabila Lokmane, Jean-François Semblat, Guy Bonnet. Local amplification of deep mining induced vibrations Part 1: Experimental evidence for site effects in a coal basin. Soil Dynamics and Earthquake Engineering, 2009, 29 (1), pp.39-50. 10.1016/j.soildyn.2008.01.014 . hal00691106

\section{HAL Id: hal-00691106 https://hal.science/hal-00691106}

Submitted on 28 Jan 2016

HAL is a multi-disciplinary open access archive for the deposit and dissemination of scientific research documents, whether they are published or not. The documents may come from teaching and research institutions in France or abroad, or from public or private research centers.
L'archive ouverte pluridisciplinaire HAL, est destinée au dépôt et à la diffusion de documents scientifiques de niveau recherche, publiés ou non, émanant des établissements d'enseignement et de recherche français ou étrangers, des laboratoires publics ou privés. 


\title{
Local amplification of deep mining induced vibrations Part 1: Experimental evidence for site effects in a coal basin
}

\author{
L. Driad-Lebeau ${ }^{\mathrm{a}, *}$, N. Lokmane ${ }^{\mathrm{a}, \mathrm{c}}$, J.F. Semblat ${ }^{\mathrm{b}}$, G. Bonnet ${ }^{\mathrm{c}}$ \\ ${ }^{a}$ Institut National de l'Environnement Industriel et des Risques (INERIS), Ecole des Mines, Parc Saurupt 54042 Nancy cedex, France \\ ${ }^{\mathrm{b}}$ Université Paris-Est, LCPC Paris, France \\ ${ }^{\mathrm{c}}$ Université Paris-Est, LaM (EA2545), France
}

Abstract

The work presented in this paper lies under the scope of a research program aiming to assess the impact of deep coal mining induced vibrations on the surface constructions. The concerned section of the program is dedicated to the study of geological site effects and their influence on the mining induced vibrations for which the experimental investigations have been carried out and developed in this paper (Part 1). The empirical methods based on $H / V$ spectral ratios have been applied on data sets provided from mining induced vibrations recorded within private residences above the deep coalmine as well as complementary measurements of ambient noise. The results evidence an amplified zone in the southern part of the Gardanne basin where drilling data confirmed the presence of particularly fractured and soft stratigraphic units. This joint analysis of induced seismicity and ambient noise enabled to validate the method based on $H / V$ ratios applied to the mining context.

Keywords: Site effects; Vibration; Mine; Seismic wave; Amplification

\section{Introduction}

Mining operations, at relatively great depths, induce a redistribution of the stress field based on the rheological and mechanical behavior of the rockmass. This can lead to substantial microseismic activity [1-6]. The rupture process generates elastic waves, which are propagated through the medium from their focus to the measurement point. On the basis of this relation between the rupture of the solid mass and the seismic activity, seismic monitoring was adopted many mines. For a few years, the concerns of the operator have exceeded the framework of safety and control of underground works because of another problem involved in the induced seismic vibrations during the coal extraction. It actually concerns the impact of the mining induced vibration (low-level seismicity) on the surface constructions, i.e. houses or buildings located close to the mine.

\footnotetext{
${ }^{*}$ Corresponding author. Tel.: +333835843 14; fax: +33383533849 E-mail addresses: lynda.driad-lebeau@ineris.fr (L. Driad-Lebeau), semblat@1cpc.fr (J.F. Semblat), bonnet@univ-mlv.fr (G. Bonnet).
}

It is commonly admitted that the induced vibration following ground motions, whatever the source, can generate an impact likely to damage the substructures. The magnitude of this impact depends on the incident signal (amplitude of the ground motion) and on the dynamic response of surface constructions. Scientific and technical research which make it possible to circumvent and understand this phenomenon are quite various and well drawn. However, these studies are exclusively based on strong motions data provided, for example, from natural seismicity. Moreover, research work on weak motion induced vibrations (i.e. mining induced seismicity) and its impact on surface constructions are to date rare, even nonexistent. The opportunity to undertake such studies raised and was carried out in the frame of a research program called "SISMINE" initiated by INERIS and sponsored by the French collieries (Charbonnages de France). The main objective of this program is to develop a numerical methodology to simulate the impact on surface constructions of weak amplitude vibrations by taking into account the wave propagation path (source, overburden, site effect, 
etc.) and the typology of the surface constructions. This research work rested on mining induced seismicity data collected over several years in instrumented private residences located straight above a deep coal mine located in southern France (coal basin of Gardanne, Provence). The SISMINE research program is subdivided into three parts, each one is devoted to a specific goal: Part 1: Experimental estimation of site effects in coal basin: Part 2 : Numerical estimation of site effects in coal basin and comparison with experimental results; Part 3: Impact of deep mining vibration on surface constructions - numerical approach.

This paper presents the results of the investigations carried out to meet the objective of the Part 1 of the research program. It consists in an empirical estimation of site amplification occurring in the surface geological structure of Gardanne (Provence. France) overlaying deep collieries where coal has been mined at depth from 1000 to $1400 \mathrm{~m}$. The main objective is to ascertain whether the geological structure characterizing the sedimentary basin amplifies the incident seismic events, inducing possible damages to surface constructions. The estimation and the analysis of the site responses are carried out by:

- using microseismic events induced by mining works and recorded at the surface in individual residences located straight above the mine;

- ambient noise data.

\section{Site description}

The Gardanne basin lies between Aix-en-Provence and Marseille (South of France) and overlays a coal field which forms the eastern part of the arc basin and it is a E-W oriented geological unit. The general tectonic features and geological setting of the basin are quite simple (Fig. 1a). After Gaviglio et al. [7], the structure is overridden by a major thrust sheet over-thrusting northward, subvertical faulting is present all over the area, most of the faults have throws inferior to $2 \mathrm{~m}$. The Gardanne basin is composed of a fluvio-lacustrine of the upper Cretaceous and the Eocene overlaying a substratum of the Jurassic (or lower

a

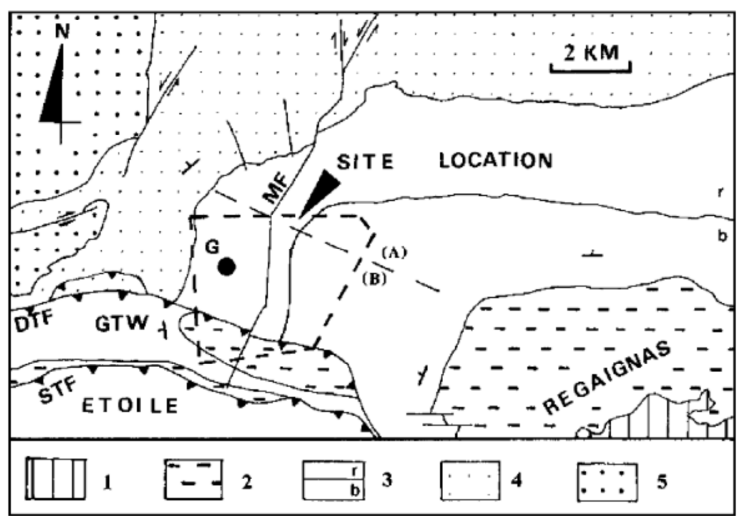

b

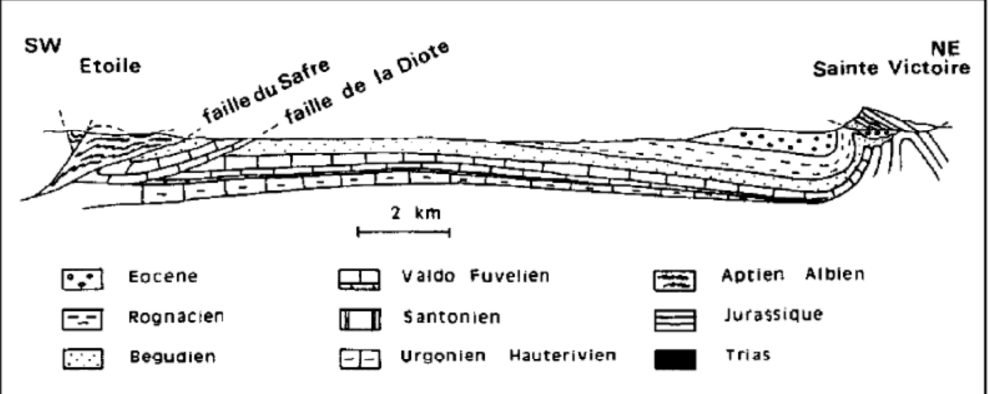

Fig. 1. (a) Geological setting and location of Gardanne mine. G: Gardanne; Etoile: Etoile thrust water table; STF: Safre thrust fault; GTW: Gardanne thrust wedge; DFT: Diote thrust fault; MF: Meyreuil fault (srike-slip-fault). (1) Upper Jurassic, (2) Campanian, (3) Begudian and Rognacian (3b, 3r), (4) Eocene, (5) Oligocene. The coalfield is located in the Campagnian limestones. (b) Geological cross section of the Gardanne basin (after Guieu [23]; Durand and Guieu [24]). 
cretaceous). The stratigraphy sequence consists mainly in marls, limestones and sandstones of the Valdonnian together with limestones of the Fuvelian (hard and brittle) with intermediate lignites (Fig. 1b). The shallower sequences are represented by clay-sandy limestones of the Rognacian and Begudian. The presence on the surface of marine abrasion and molasses deposits has marked the influence of a sedimentary episode of the Miocene.

Among the eight coal levels having been exploited since the middle age, the last seam mined until the closing of the mine (2003) was the so-called "Grande Mine", that is the most significant layer $(2.5 \mathrm{~m}$ thick in average) located depths ranging from 1000 to $1400 \mathrm{~m}$. The coal layers were worked with a long wall caving method that uses two roadways and extracts coal along a straight front having a large longitudinal extension. The stopping area close to the face is kept open to provide a secure zone for the staff and the mining equipment.

\section{Mining induced seismicity in Gardanne mine}

\subsection{Permanent seismic monitoring}

The mine of Gardanne has been for many years the seat of an intense induced seismic activity as well as a recurrent rockbursts. The latter consists of a brutal expulsion of the worked seam simultaneous with a violent shock mainly felt in the vicinity of the coal seam where it can cause significant damages such as roadways and pillars closures or coalburst. The mining induced seismic activity occurs in different ways depending on natural conditions and on the geometry of the mining (successive panels mined skin to skin or with small pillars in multiple layers). Major dynamic events are generally associated with an important seismic activity. In order to monitor the underground works and in an objective of prevention of rockburst risk zones, the owner has installed a permanent seismic network straight above the mine, in the early 1990s. This network, which was constantly improved in azimuthal coverage as well as in numerical means for real time data processing, enabled the recording of tens of thousands seismic events with a local magnitude varying from 1.3 (detection threshold) to 3.5 (strongest event). Note that it is generally accepted that the strong events (local magnitude greater than 3) are mainly due to geological discontinuities such as faults [6].

The global seismic activity recorded since 1994 by the permanent network is shown in Fig. 2. Note the clear reduction of the seismic activity mainly related to the optimization of the mining configuration (geometry) and preventive actions (ground relaxation, in situ measurements, back analysis, etc.) aiming at anticipating dynamic instabilities responsible of the seismic activity.

\subsection{Mobile seismic monitoring network}

Mining induced seismicity was for a long time, felt at the surface straight above the mine where many residences exist. Therefore, in 1994, a complementary seismic network (mobile network) has been installed in private residences (basement) in order to analyze the measured vibrations originated from underground mining works (Fig. 3). The measurements are carried out using three autonomous stations, each composed of a seismic data logger and a $1 \mathrm{~Hz}$ three component geophone. The stations are moved to other residence after a given period of measurements, which depends on the progress of the underground mining works. Vibration recordings coming from the so-called "mobile network" constitute a significant database for each instrumented residence. As an indication, during the period from 1998 to 1999, the seismic station at a residence called "LAG", located straight above running works in the

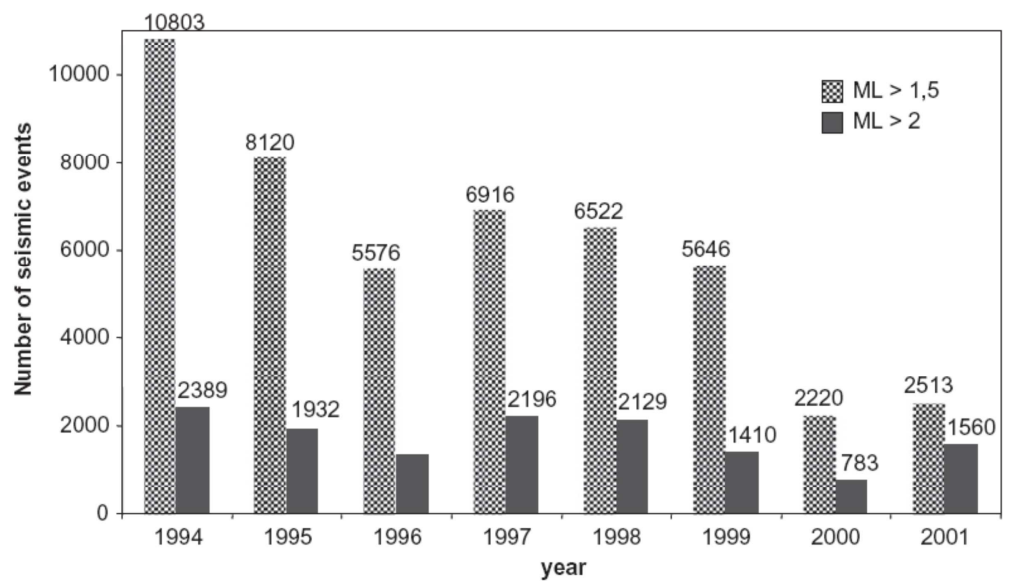

Fig. 2. Induced seismic activity recorded by the permanent monitoring network during mining works in the Gardanne mine from 1994 to 2001 


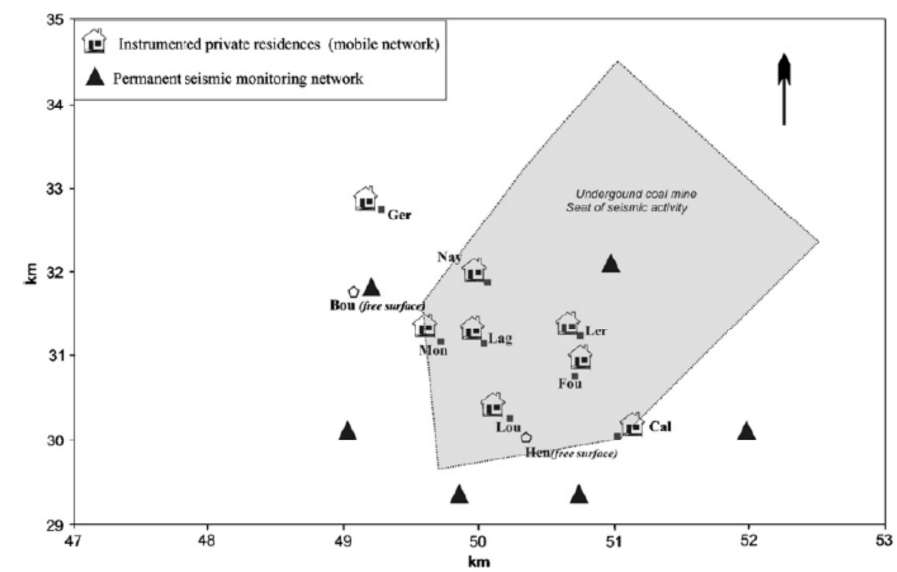

Fig. 3. Instrumented residences and permanent seismic network located above the underground coal mine.

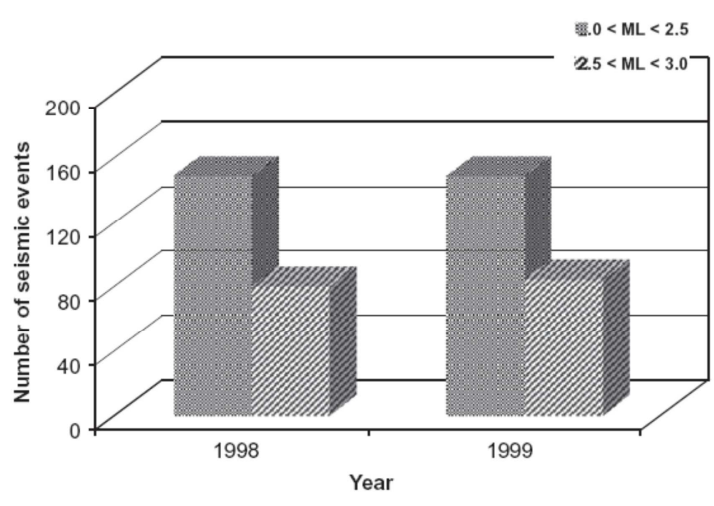

Fig. 4. Seismic activity recorded during the mining works at residence LAG.

Table 1

Geological nature of the sub-surface structure of the instrumented residences

\begin{tabular}{ll}
\hline Site & Geology \\
\hline FOU & Alluvial deposits \\
BOU & Limestones \\
NAY & Limestones -faulting zone \\
MON & Limestones \\
LAG & Marls \\
LER & Alluvial deposits \\
GER & Limestones \\
LOU & Marls \\
CAL & Limestones \\
HEN & Limestone-marls \\
\hline
\end{tabular}

south-eastern part of the collieries, recorded more than 400 events of local magnitude ranging between 2 and 3 (Fig. 4). Note that the seismic activity is recorded at the same time by both monitoring networks (permanent and mobile), the local magnitude is estimated from the recordings of the permanent network. The foundation of the instrumented residences lies on different geological units as described in Table 1. It is precisely the amplification effect due to the variability of the mentioned geological units that are contained in this study.

\section{Experimental estimation of site amplification}

Since more than one century, the disparity of the damage caused by a seismic vibration in various points located at the same distance from the source was observed after many earthquakes. It has been understood for some time that this is related to "site effects "due to sedimentary deposits near the surface. Indeed, the soft geological layers overlaying the competent bedrock induce resonance and amplification of the incident ground motion vibration. Many studies have demonstrated the ability of surface geologic conditions, physical parameters and mechanical characteristics of the ground, to alter observed seismic motions [8-10]. These phenomena related to amplification of seismic waves involve very often a lengthening of the strong phase of the signal inducing the damage of surface constructions. Hence, it appears obviously important to estimate and to take into account the site effects in the assessment of the impact of mining induced vibrations on surface constructions.

\subsection{Methodology and general considerations}

The estimation of site resonance and amplification is carried out by using two quantitative methods based on the horizontal to vertical ratio of mining induced seismic events (transfer function method [11]) and ambient noise data $[12,13]$. The transfer function method using seismic recordings assumes that, at low frequencies, 
the vertical component of the displacement is less or not affected by local amplification, whereas the horizontal component is strongly affected. Thus, the principle of the method is to compute, for a given site, the spectral ratio $H / V(f)$ between the Fourier transform components of the recordings $H(t)$ and $V(t)$ of the horizontal and vertical motions and to identify on this ratio the fundamental resonance at low frequency. However, the amplitude of the resonance must be considered with caution owing to the fact that the amplitude of the $H / V$ ratio represents a relative measurement of the local amplification [14].

On the other hand, it is now well admitted that the spectrum of ambient noise is influenced by subsurface geology. It is assumed that the low frequency range of the noise corresponds to surface waves propagation (Rayleigh and Love waves) while the higher frequencies are mainly assigned to body waves. Hence, the method based on the $H / V$ ratio of ambient noise has been introduced and is used to identify, for a given site, potential amplification and the related resonance frequency [13]. A large number of experiments have shown that the ambient noise $H / V$ procedure can be successfully applied for identifying the fundamental resonance frequencies of sedimentary deposits [15-17]. These observations were supported by several theoretical 1-D investigations to characterize the noise wavefield and its ability to provide information about site conditions [18-20]. Theoretical investigations have shown that the dominant $H / V$ resonance frequency derived from noise and vertical $\mathrm{S}$ wave is in a good agreement; thus, the $H / V$ ratio gives a reliable indication of the resonance frequency of a horizontal layered structure. In terms of amplitude, i has been highlighted that the $H / V$ peak is very sensitive to the velocity contrast and to other parameter such as Poisson's ratio within the sedimentary structure Moreover, Bonnefoy-Claudet et al. [20] evidenced a dependency between the source location of the ambien noise and the $H / V$ ratio shape (one or two peak resonance).

In the following, the $H / V$ ratio technique is used to estimate the site amplification and resonance on the basis of coal mining induced seismicity on one hand and of ambient noise data collected during a survey in Gardanne basin on the other hand. We believe that the use of mining induced seismicity should provide the same information on subsurface characteristics as earthquake data (in fact, site amplification). Indeed, a seismic activity is the consequence of a readjustment of constraints within the rock solid mass by fracturing or by slip on pre-existent fractures. From a seismological point of view, there is no fundamental difference between the generation of seismicity induced by mining or by vibrations of tectonic origin. Indeed, the events recorded by monitoring networks in mining conditions show features similar to those of the recordings of usual tectonic seismic motions (phases $\mathrm{P}$ and $\mathrm{S}$, conversions, attenuation, etc.)

\section{2. $H / V$ ratio from mining induced seismicity}

4.2.1. Data set

The induced seismic data provided from the mobile network described above have been processed in frequency domain by running the FFT on the S-wave arrivals. We have selected for each residence all events of magnitude that are greater than 2.5 , which constitute potentially interesting vibrations in terms of the impact on surface constructions. In addition, signal to noise ratio was analyzed in the frequency domain to refine the selection of the data set. The example shown in Fig. 5 testifies the good quality of the recordings with a high signal to noise ratio $(\sim 100)$ for all frequencies particularly in the considered frequency band $(1-10 \mathrm{~Hz})$. Hence, we have used more than 20 events with a local magnitude greater than 2.5 for each of the 10 -instrumented sites $(8$ residences and 2 free-surface sites, Fig. 3) to compute the ratios between horizontal (resultant) and vertical spectrum of the S-wave amplitudes. The average $H / V$ ratio is then estimated for each site and represented as a function of frequency plus/ minus one standard deviation.

\subsubsection{Analysis}

Generally, the spectral $H / V$ ratios illustrated in Fig. 6 highlight significant variations in resonance's and amplitude peaks (evidencing amplification) at the investigated sites. It is possible to distinguish clearly two groups. In the first one, resonance's are observed in the frequency band $3-8 \mathrm{~Hz}$ with amplitudes ranging from 3 to 13 at sites LAG, LER, FOU, HEN, MON and NAY (Groupe1, Fig. 6a). The response of the site $\mathrm{LAG}$, which ranges overall between 2 and $8 \mathrm{~Hz}$, is characterized by a dominant resonance at $5.5 \mathrm{~Hz}$. This resonance observed with an amplitude of approximately 11, might correspond, according to the outcrops of the site, with the marls of lower Rognacien. These marls are under a cover of alluvium; thus, the impedance contrast between these two formations would explain this relatively strong resonance.

The site LER presents more significant fluctuations in its spectral response of the $H / V$ ratio. A dominant resonance is observed at $4.5 \mathrm{~Hz}$ with amplitude of 8 related primarily to the alluvial formations characterizing the site. The maximum amplitude (13) is observed with the site FOU.

The dominant resonance observed at $3.9 \mathrm{~Hz}$ might be related to the alluvia that characterize site FOU. In comparison to the site LER (alluvia), the observed amplitude at site FOU is particularly strong owing to the fact that the FOU alluvia are located in a zone containing ground water at low depth.

The sites HEN and NAY, where outcrops are mainly marl-limestone, present a weak resonance (amplitude of nearly 3-4) at 3-6 Hz. This observation is coherent with the geological setting where the limestone dominates. In this particular case, the amplification effect is not very significant. It is interesting to note the response of the site MON, which presents a broad resonance at $4.5 \mathrm{~Hz}$ with an 

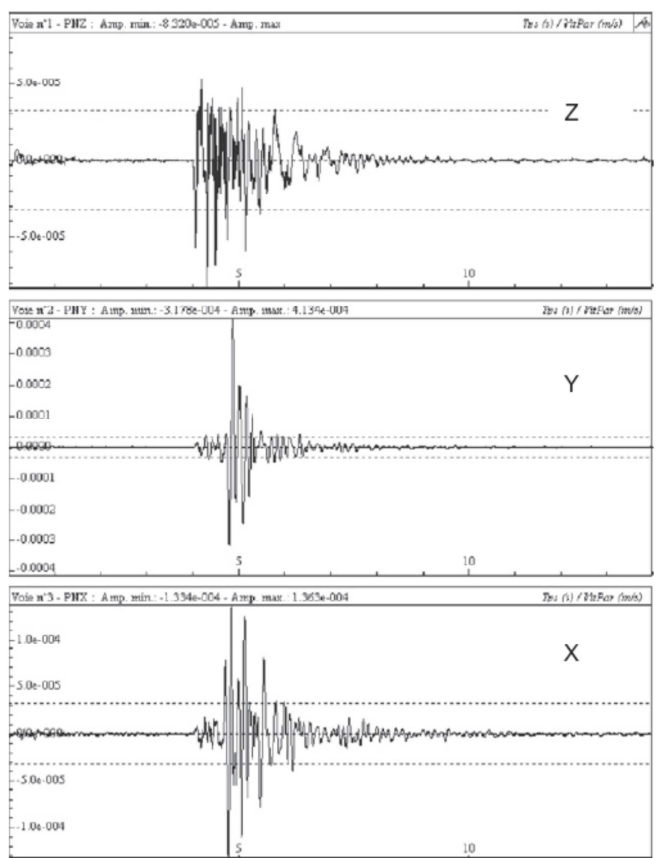

b

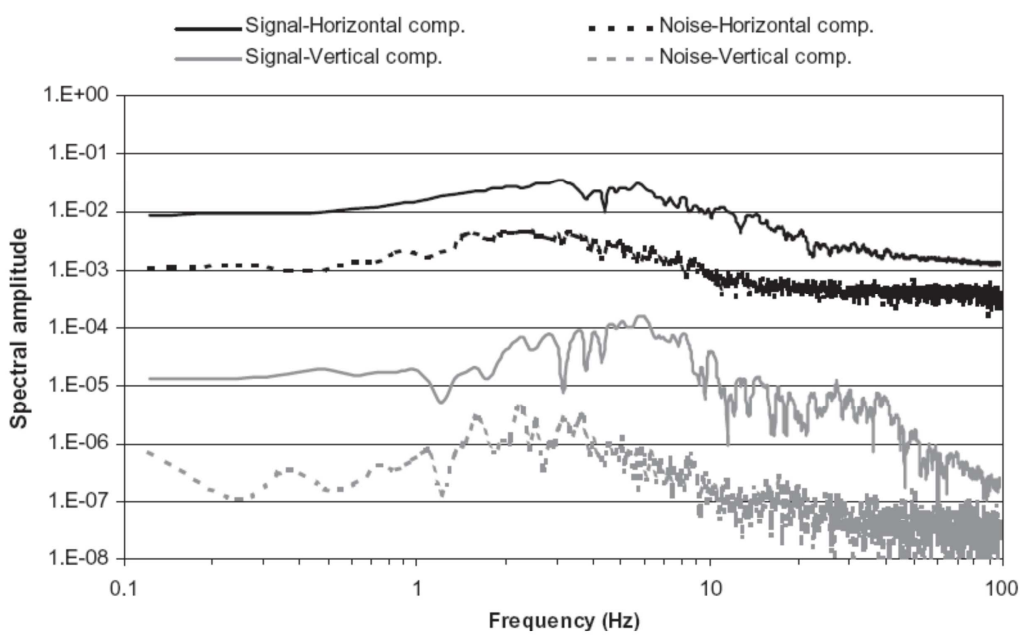

Fig. 5. Example of mining induced vibration recording at residence LAG (a) and the corresponding signal and noise spectrum (b).

amplitude of 7. Indeed, according to the geology (limestone-marls), the $H / V$ ratio would be expected close to that of the site HEN. If we admit that the geological setting of the site MON is realistic, the observed amplitude could be related to a topographic effect. Indeed, the corresponding house is located on the slope of a hill, which culminates at $210 \mathrm{~m}$.
The second group (Fig. 6b) concerns the sites GER, $\mathrm{CAL}$ and BOU overlying a massive limestone layer. The spectral $H / V$ ratios highlight a flat response at all frequencies, except the site BOU where a resonance peak appears at $10 \mathrm{~Hz}$. Indeed, the geology of this site is particularly complex. It overhangs the quasi-horizontal so-called "Diote" fault located near to the surface. 
a
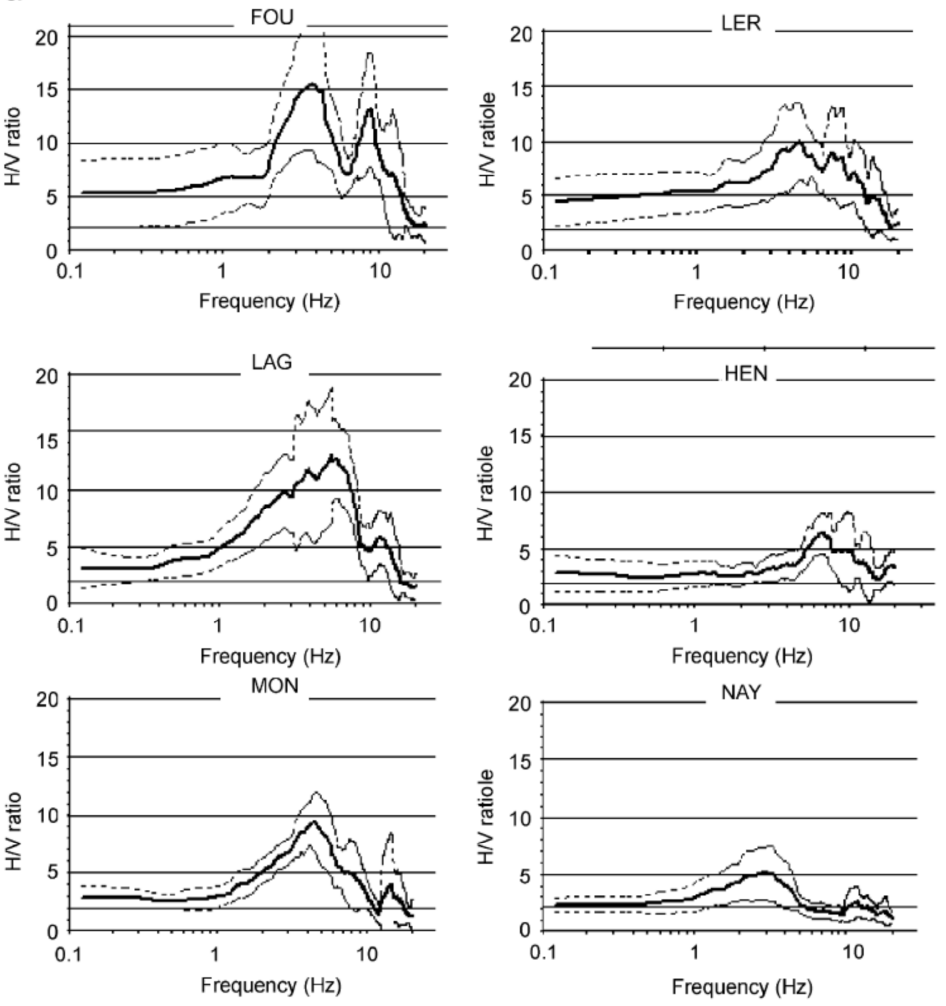

b
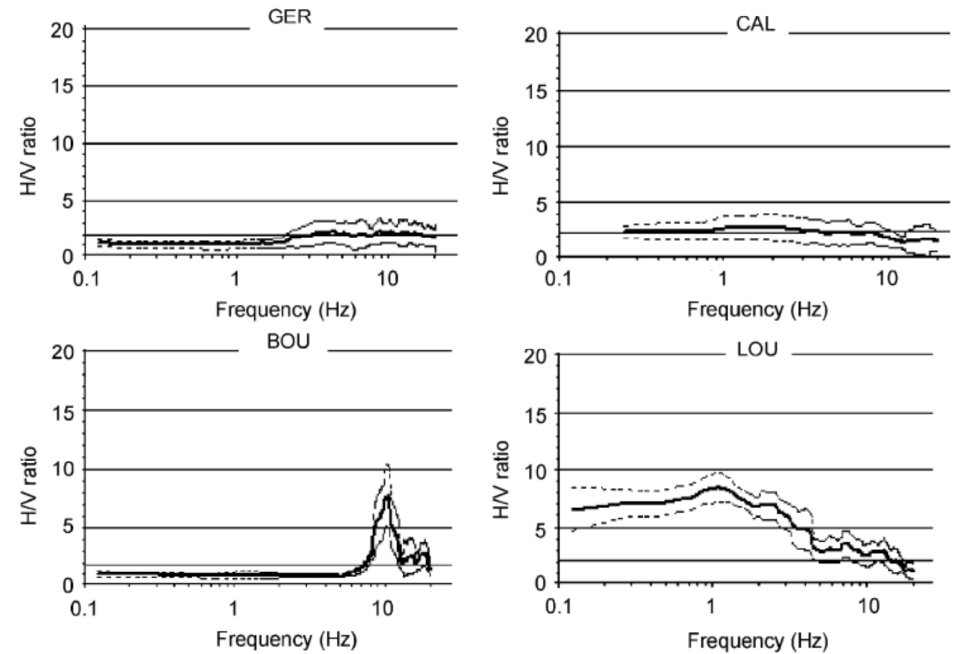

Fig. 6. (a) $H / V$ spectral ratios from mining induced seismic data (group 1). The thick line and the dotted lines correspond, respectively, to the average $H / V$ ratios for each residence and plus/minus one standard deviation. (b) $H / V$ spectral ratios from mining induced seismic data (group 2). The thick line and the dotted lines correspond, respectively, to the average $H / V$ ratios for each residence and plus/minus one standard deviation. 
The spectral response observed at $10 \mathrm{~Hz}$ might be related locally to the effect of the disturbances induced by the fault. On the other hand, the site LOU presents a typical spectral response related to comparatively strong ground attenuation. No resonance is highlighted but one notes on the $H / V$ ratio curve an attenuating slope showing amplitudes decreasing with the frequency. This phenomenon is typically due to an inelastic attenuation.

\subsubsection{Microzoning}

A microzoning map was built to highlight zones in the coal basin sensitive to site amplification. The calculated $H / V$ ratios were used to represent the "relative" spatial variation of the maximum amplitude corresponding to the observed dominant resonance. Thus, we obtained two microzoning maps in the selected frequency bands of 2-6 and $6-10 \mathrm{~Hz}$ (Fig. 7), with the exception of the site BOU that is characterised by a resonance peak at $10 \mathrm{~Hz}$. The two maps appear quite similar and show that the amplitude values are relatively large in the southern part of the basin, likely due to the underlying sediments. Note that, as expected, the sites LER, LAG and FOU are in the heart of a potential amplification zone in opposition to the sites GER, BOU and CAL. These results show that, even if the absolute spectral amplitudes obtained from $H / V$ interpretation must be used with caution, their relative values at
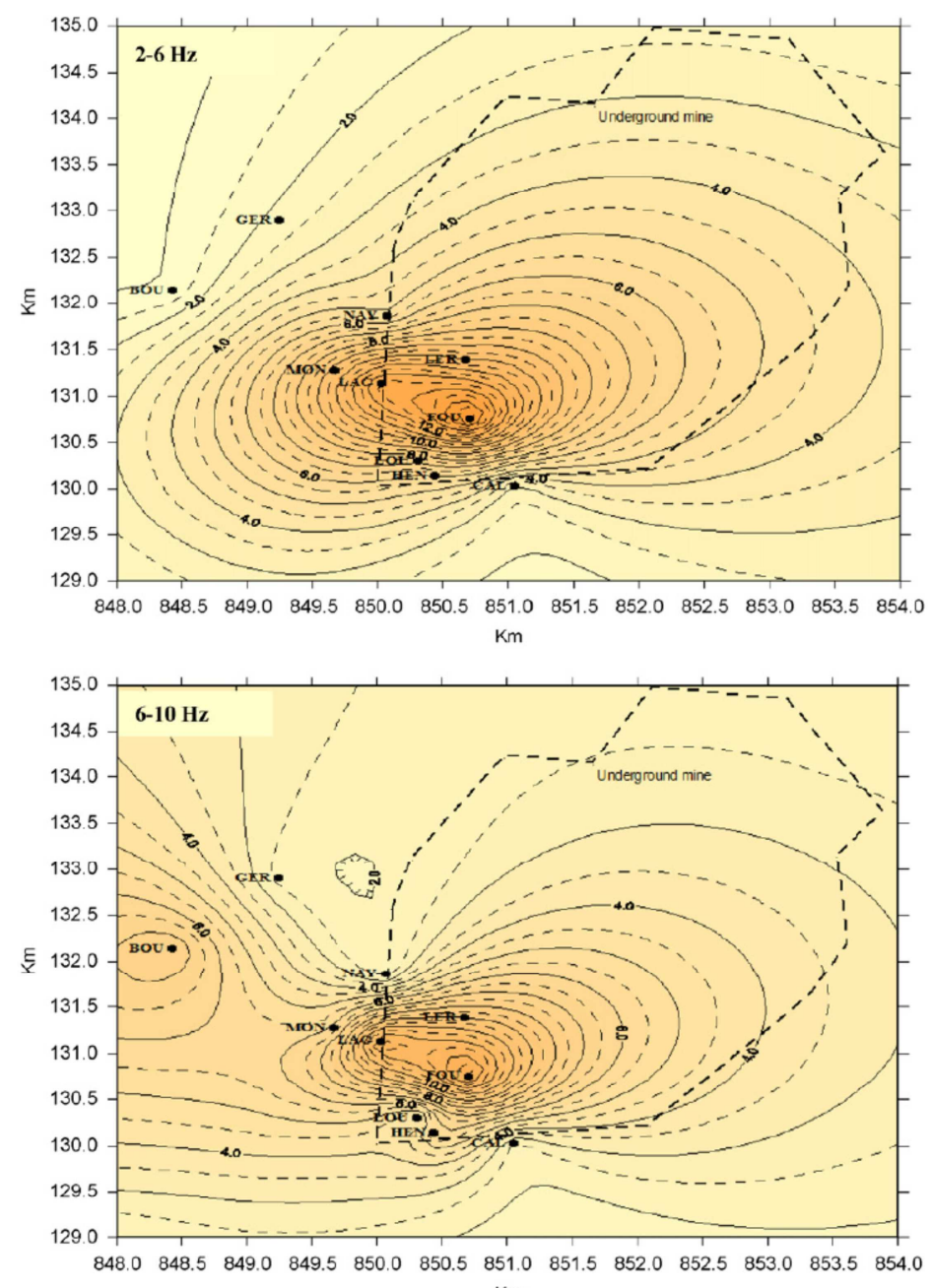

Fig. 7. Microzoning map of site amplification provided from mining induced seismicity recorded at surface residences. The $H / V$ dominant peaks are presented in the frequency bands of $2-6 \mathrm{~Hz}$ (top) and $6-10 \mathrm{~Hz}$ (above). 
different locations within a same set of measurements constitute a means to identify the zones of seismic amplification.

Finally, the experimental estimation of site amplification using induced mining vibrations revealed to be of great interest so that further investigations were carried out to increase the geological-site coverage and allow a better estimation of the frequency dependent resonance. Therefore, new data provided by ambient noise measurements in the basin have been collected to complete and enrich the information on the site amplification obtained from the induced seismicity.

\subsection{H/V ratio from ambient noise data}

More than 20 free-field noise measurement locations have been investigated in the basin using $0.2 \mathrm{~Hz}$ velocity meters and a Lennartz Marslite acquisition system. The $H / V$ spectral ratios were computed on optimal pre-selected windows of $16 \mathrm{~s}$ duration that show the best "quality" of noise recording. For each window, the spectral $H / V$ ratio was calculated and smoothed using a procedure that provides a better accuracy at high frequencies [21]. Fo each noise event, the averaged $H / V$ ratio over all available windows is then computed.
The results evidence a moderate to weak amplification effect in the basin. Most of the sites show a more or less flat response except for two single sites (points 12 and 15) characterised by a relatively amplified resonance at frequencies 5 and $7 \mathrm{~Hz}$ (Fig. 8). Note that the geographical position of these two sites is close to the amplification zone (southern part of the basin) identified from the mining seismicity analysis of the recordings relative to residences LAG, LER and FOU. The $H / V$ ratios of the residence LAG and the noise free-field site at point 15 are plotted together, using a same scale for comparison (Fig. 9). We observe that both spectral responses highlight a single resonance at $7 \mathrm{~Hz}$, but the one relative to the noise data shows a lower amplitude. This last observation confirms the assessment according to which the amplitude of the $H / V$ peaks must be considered cautiously, taking into account the conclusions of the theoretical investigations mentioned above (see [18]). Indeed, the sources of the ambient noise and natural or induced earthquakes are not of comparable nature. The noise waves are associated with microtremors generated by surface sources such as wind, road traffic, trains, industrial activity, etc. These waves consist of a mixture of surface and body waves which have not travelled through the whole sedimentary structure unlike the waves coming from mining induced seismicity.
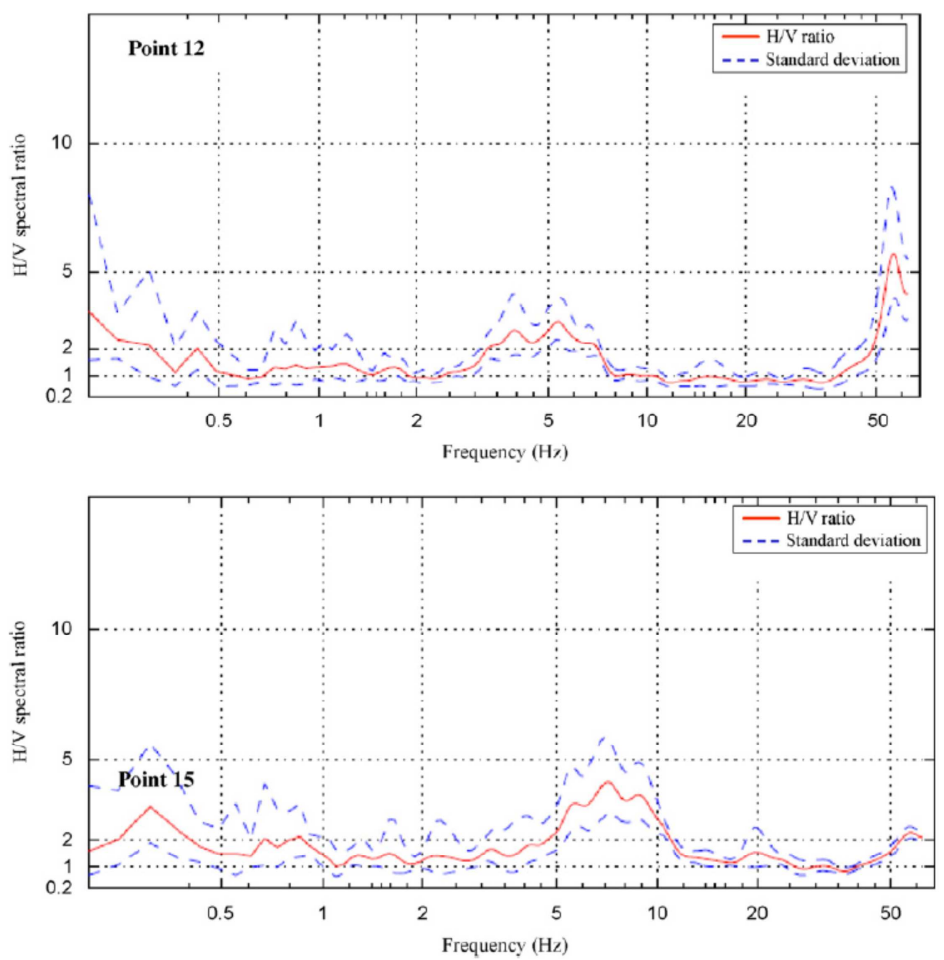

Fig. 8. Example of $H / V$ ratio from ambient noise at points 12 and 15 close to the residence LAG 


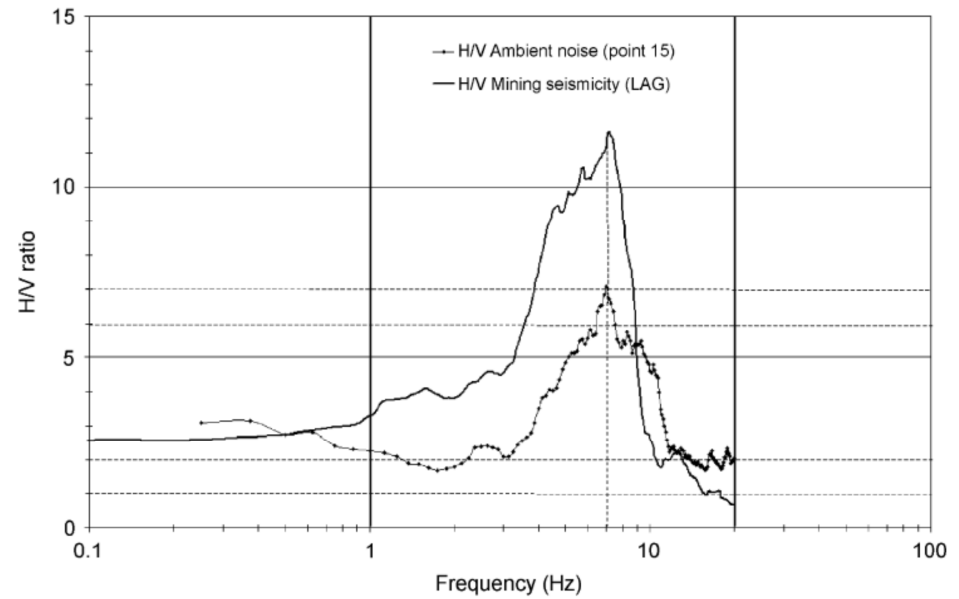

Fig. 9. Comparative analysis of $H / V$ ratios at residence LAG (vibration data) and noise measurement point 15 . Note the low amplitude level observed on the noise $H / V$ spectral response.

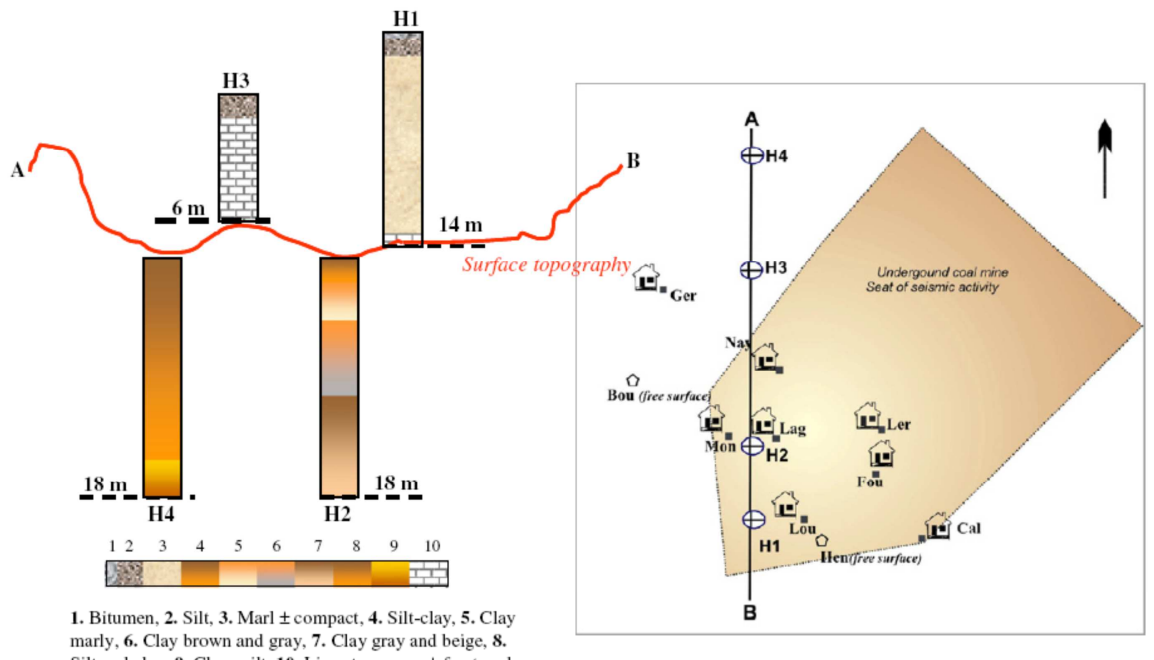

Fig. 10. Position of the drilling holes along the North-South axis in the basin (right) and the obtained stratigraphic vertical sections (left).

Furthermore, the stresses involved in the ambient noise are very low compared with those produced during mining operations.

According to these observations, in contrast to the resonance frequency, the observed amplitudes of the $H / V$ peaks provided from ambient noise and seismicity data are not expected to be comparable.

\subsection{Stratigraphic analysis}

The interpretation of the site amplification identified from the induced seismicity was based on available geological information provided from borehole investigations and surface outcropping at the scale of the coal basin. However, this global information does not reveal a possible disparity of the stratigraphy in the first meters of the basin that might be related to the observed amplification effect deduced from $H / V$ ratios. In addition, a better stratigraphic sampling is of great interest in order to draw back a possible ambiguity on the amplitude of the $H / V$ peaks provided from noise and seismicity recordings. Finally, in the perspective of modelling the site effects, it appeared fundamental to identify precisely the stratigraphy and the mechanical properties of the concerned geological layers. Therefore, a drilling campaign 
has been carried out in the Gardanne basin thanks to a close collaboration of the mine operator (Charbonnages de France). Three destructive and 1-cored boreholes have been drilled along a NS axis in the basin until the substratum or the hard rock could be reached (Fig. 10). The borehole noted $\mathrm{H} 2$ implemented in the vicinity of the residence LAG was partly cored up to the depth of $8 \mathrm{~m}$; the drilling went on in a destructive mode to reach the $18 \mathrm{~m}$ depth. Diagraphy measurements were done in each borehole to estimate the density along with the $\mathrm{P}$ and $\mathrm{S}$ wave velocities. The latter were then compared to the estimated values provided from laboratory tests undertaken on the cored samples for mechanical characterisation (borehole $\mathrm{H} 2$ ).

The analysis of the borehole data (stratigraphy and diagraphy) along the NS vertical section evidenced an unconsolidated material filling between the boreholes $\mathrm{H} 1$ and $\mathrm{H} 3$ yielding low densities and velocities ( $\mathrm{P}$ and $\mathrm{S})$ at least up to a depth of $18 \mathrm{~m}$. The most soft and fractured stratigraphic units were met in the borehole $\mathrm{H} 2$ (vicinity of residence LAG) made up mainly of clays and silts with inclusions of marly-clays characterized by relatively low $\mathrm{P}$ wave velocities (Fig. 10).

\section{Conclusions}

In the frame of a research program centred on the impact on surface constructions of mining induced seismicity, we have conducted two experimental studies of site amplification in a sedimentary basin in which a large coal layer has been actively mined for more than 10 years.

During the exploitation, the operator has monitored vibrations within private residences located at the surface above the underground mine in which seismic activity was felt and might be at the origin of possible damage. The recorded mining induced vibrations have been exploited to estimate the site amplification in the basin using $H / V$ spectral ratio method that is commonly applied on earthquake data. The results evidenced site amplifications mainly in the southern part of the basin where a single resonance appears at frequencies below $10 \mathrm{~Hz}$. Ambient noise measurements have been carried out in order to increase the data coverage in the basin. The noise data analysis highlighted resonance frequencies similar to those provided from induced mining seismicity. Nevertheless, we have noted a substantial difference in the $H / V$ peaks that are much lower for noise data, likely due to the nature and the position in depth of the ambient noise sources, compared to the sources involved in seismic activity. However, both $H / V$ ratios obtained from induced seismicity and ambient noise data show evidence for a site amplification zone in the southern part of the basin (sites LAG, FOU, MON) and a flat response on the sides of the basin where the geological setting is characterised mainly by competent limestone. In addition, a stratigraphical identification carried out from drilling campaign along an NS axis of the basin made it possible to validate the observed site amplification. Indeed, the zone related to a relatively high amplification, which is centred on the site LAG in the southern part of the basin, is in good agreement with soft and fractured geological units met during the drilling and identified on cored samples at the laboratory. In the companion paper, the results obtained from the experimental investigations will be confronted to those obtained from a numerical modelling of site effects based on the stratigraphical and mechanical information provided from drilling data and laboratory tests [22].

The experimental investigations for site effect estimation showed a coherence in terms of resonance frequencies, between the $H / V$ ratio analysis of mining induced seismicity and ambient noise confirming the existence of site amplification in the Southern part of the basin. This joint analysis of induced seismicity and ambient noise made it possible to compare the use of two methods based on $\mathrm{H} / \mathrm{V}$ ratios in the context of mining induced seismicity.

\section{References}

[1] Ben Slimane K, Besson JC, Mandereau G, Chambon C. Seismic monitoring: a tool for planning mining sites submitted to dynamic phenomena. In: Third Franco-Polish symposium, vol. XI(1-2), Wroclaw, 1990. p. 55-68.

[2] Linkov A, Zoubkov V, Al Heib M. Computer aided analysis of stressed state and rockburst hazard in veins and coal seams influenced by faults. In: Gürtunca RG, Hagan TO, editors. SAREST 97. First southern African rock engineering symposium proceedings, Johannesburg, South Africa, 1997.

[3] Kanelo K, Sugawara K, Obara Y. Rock stress and microseismicity in a coal burst district. In: Fairhurst, editor. Rockburst and seismicity in mines. Rotterdam: Balkema; 1999.

[4] Senfaute G, Chambon C, Bigarre P, Guise Y, Josien JP. Spatial distribution of mining tremors and the relations to rockburst hazard. J Pure Appl Geophys 1997;150:451-9.

[5] Senfaute G, Al Heib M, Josien JP, Noirel JF. Detection and monitoring of high stress concentration zones induced by coal mining using numerical and microseismic methods. In: Rockburst and Seismicity in Mines-South African Institute of Mining and Metallurgy, 2001.

[6] Driad-Lebeau L, Lahaie F, ALHeib M, Josien JP, Bigarré P, Noirel JF. Seismic and geotechnical investigation following rockburst in a complex French mining district. Int J Coal Geol 2005;64: 66-78.

[7] Gaviglio P, Bigarré P, Baroudi H, Piguet JP, Monteau R. Measurements of natural stress in a provence mine (Southern France). Eng Geol 1996;44:77-92.

[8] Borcherdt RD. Effect of local geology on ground motion near San Francisco bay. Bull Seismol Soc Am 1970;60:26-61.

[9] Tucker BE, King JL. Dependence of sediment-filled valley response on input amplitude and valley properties. Bull Seismol Soc Am 1984; 74:153-65

[10] Aki K. Local site effects on weak and strong ground motion. Tectonophysics 1993;218:93-111.

[11] Longoston CA. Structure under Mount Rainier, Washington, inferred from teleseismic body wave. J Geophys Res 1979;84(B9): 4749-62.

[12] Nogoshi M, Igarachi $T$. On the amplitude characteristics of microtremor (Part 2). J Seismol Soc Jpn 1971:23:264-80.

[13] Nakamura YA. Method for dynamic characteristic estimation of subsurface using microtremors of the ground surface. Q Rep Railw Tech Res Inst 1989;30:25-33.

[14] Bard PY. Microtremor measurements: a tool for site effect estimation? In: Proceedings of the second international symposium 
on the effects of the surface geology on seismic motion, vol. 3, Yokohoma, Japan, 1998. p. 1251-1279.

15] Lermo J, Chavez-Garcia FJ. Site effects evaluation using spectral ratios with only one station. Bull Seismol Soc Am 1993:83:1579-94.

[16] Fäh D. Microzonation of the city of Basel. J Seismol 1997;1:87-102

[17] Seekins LC, Wennerberg L, Marghereti L, Liu H-P. Site amplification at five locations in San Fransisco, CA: a comparison of S waves, codas, and microtremors. Bull Seismol Soc Am 1996;86:627-35.

[18] Lachet C, Bard PY. Numerical and theoretical investigations on the possibilities and limitations of Nakamura's technique. J Phys Earth 1994:42:377-97.

[19] Lermo J, Chavez-Garcia FJ. Site effect evaluation at Mexico City dominant period and relative amplification from strong motion and microtremor records. Soil Dyn Earthquake Eng 1994;13:413-23.
[20] Bonnefoy-Claudet S, Cornou C, Bard PY, Cotton F, Moczo P, Kristek J, et al. H/V ratio: a tool for site effects evaluation. Results from 1-D noise simulations. Geophys J Int 2006;167:827-37.

[21] Konno K, Ohmachi T. Ground motion characteristics estimated from spectral ratio between horizontal and vertical components of microtremor. Bull Seismol Soc Am 1998;88(1):228-41.

[22] Semblat JF, Kham M, Parara E, Bard PY, Pitilakis K, Makra K, et al. Site effects: basin geometry vs soil layering. Soil Dyn Earthquake Eng 2005;25(7-10):529-38.

[23] Guieu G. Un exemple de tectonique tangentielle: l'évolution du cadre montagneux de Marseille. Bulletin de la société Géologique de France No. $4 ; 1967$. pp. 610-630.

[24] Durand JP, Guieu G. Cadre structural du Bassin de l'Arc. Revue de l'Industrie minérale; juin 1980. pp. 13-25. 